\title{
Gradients in intact polar diacylglycerolipids across the Mediterranean Sea are related to phosphate availability
}

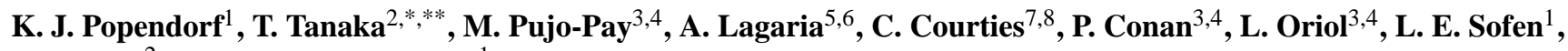 \\ T. Moutin ${ }^{2}$, and B. A. S. Van Mooy ${ }^{1}$ \\ ${ }^{1}$ Dept. of Marine Chemistry and Geochemistry, Woods Hole Oceanographic Institution, MS \#4, Woods Hole, \\ MA 02543, USA \\ ${ }^{2}$ Université de la Méditerranée, CNRS, Laboratoire d'Océanographie Physique et Biogéochimique, UMR 6535, \\ Centre d'Océanologie de Marseille, Campus de Luminy, Case 901, 13288 Marseille cedex 09, France \\ ${ }^{3}$ CNRS, UMR 7621, LOMIC, Observatoire Océanologique, 66651 Banyuls/mer, France \\ ${ }^{4}$ UPMC Univ Paris 06, UMR 7621, LOMIC, Observatoire Océanologique, 66651 Banyuls/mer, France \\ ${ }^{5}$ INSU-CNRS, Laboratoire d'Océanologie et des Géosciences, UMR 8187, Université Lille Nord de France, ULCO, \\ 62930 Wimereux, France \\ ${ }^{6}$ Hellenic Centre for Marine Research, Inst. of Oceanography, 71003 Heraklion, Crete, Greece \\ ${ }^{7}$ CNRS, UMS 2348, Observatoire Océanologique, 66651 Banyuls/mer, France \\ ${ }^{8}$ UPMC Univ Paris 06, Laboratoire ARAGO, Observatoire Océanologique, 66651 Banyuls/mer, France \\ * now at: INSU-CNRS, Laboratoire d'Océanographie de Villefranche, UMR 7093, 06230 Villefranche-sur-Mer, France \\ *** now at: Université Pierre et Marie Curie-Paris VI, Laboratoire d'Océanographie de Villefranche, UMR 7093, 06230 \\ Villefranche-sur-Mer, France
}

Received: 31 July 2011 - Published in Biogeosciences Discuss.: 8 August 2011

Revised: 1 December 2011 - Accepted: 2 December 2011 - Published: 20 December 2011

\begin{abstract}
Intact polar membrane lipids compose a significant fraction of cellular material in plankton and their synthesis imposes a substantial constraint on planktonic nutrient requirements. As a part of the Biogeochemistry from the Oligotrophic to the Ultraoligotrophic Mediterranean (BOUM) cruise we examined the distribution of several classes of intact polar diacylglycerolipids (IP-DAGs) across the Mediterranean, and found that phospholipid concentration as a percent of total lipids correlated with phosphate concentration. In addition, the ratios of non-phosphorus lipids to phospholipids - sulfoquinovosyldiacylglycerol (SQDG) to phosphatidylglycerol (PG), and betaine lipids to phosphatidylcholine (PC) - were also found to increase from west to east across the Mediterranean. Additionally, microcosm incubations from across the Mediterranean were amended with phosphate and ammonium, and in the course of several days nutrient amendments elicited a shift in the ratios of IP-DAGs. These experiments were used to assess the relative contribution of community shifts and physiological response to the observed change in IP-DAGs across the Mediterranean. The
\end{abstract}

Correspondence to: K. J. Popendorf (kpopendorf@whoi.edu) ratio of SQDG to chlorophyll- $a$ was also explored as an indicator of phytoplankton response to nitrogen availability. This study is the first to demonstrate the dynamic response of membrane lipid composition to changes in nutrients in a natural, mixed planktonic community.

\section{Introduction}

Lipids form the membranes of cells and comprise a substantial fraction of planktonic carbon and phosphorus (Wakeham et al., 1997; Van Mooy and Fredricks, 2010). As such, lipids play key roles in the biogeochemical cycles of carbon and phosphorus in the ocean (Suzumura and Ingall 2001), and their synthesis poses a significant cellular nutrient requirement (Van Mooy et al., 2008, 2009). Bacterial and eukaryotic marine membranes are composed mainly of intact polar diacylglycerolipids (IP-DAGs) and these compounds are valuable tools for the study of microbes in the environment (Rütters et al., 2002; Sturt et al., 2004). These IP-DAGs are classified by the structure of their headgroups, which are differentiated by containing phosphorus, nitrogen, sulfur, sugars, or some combination of these (Guschina and Harwood, 2006; Kato et al., 1996; Oliver and Colwell, 1973; Sato,

Published by Copernicus Publications on behalf of the European Geosciences Union. 
1992; Van Mooy and Fredricks, 2010). The relative abundance of different headgroups within a membrane contributes to the cellular demand for limiting nutrients. Because phosphorus is in low supply in much of the ocean and is in high cellular demand, the constraint imposed by production of phospholipids is nontrivial for marine microbes (Van Mooy et al., 2006, 2008, 2009).

Different groups of plankton contain different arrays of IPDAG headgroups (Popendorf et al., 2011; Van Mooy et al., 2006), such that a community dominated by phytoplankton could be expected to have a different total IP-DAG composition than a community dominated by heterotrophic bacteria. Some types of plankton have been shown to be capable of substituting non-phosphorus lipids for phospholipids in conditions of phosphorus stress (Benning et al., 1993, 1995; Martin et al., 2011; Minnikin et al., 1974; Van Mooy et al., 2009), adjusting the composition of their membrane as a physiological response to nutrient conditions. This physiological response has been demonstrated in culture, but has not previously been observed in a natural, mixed planktonic community. It has been observed that the ratios of nonphosphorus lipids to phospholipids in the water column were lower in the phosphate-replete South Pacific and higher in the phosphate-depleted Sargasso Sea (Van Mooy et al., 2009), but we posit that this difference in IP-DAG ratio could be attributed to either differences in planktonic community structure or differences in the physiological adaptation of plankton to low nutrients. Deconvolving the contribution of these two mechanisms would provide deeper insights on the ecological and oceanographic meaning of IP-DAG ratios in the environment.

The Mediterranean Sea is well suited for a study of the influence of phosphate depletion on IP-DAG distribution, as it is characterized by exceptionally low concentrations of phosphate and high ratios of dissolved N:P (Krom et al., 1991; Moutin and Raimbault, 2002; Pujo-Pay et al., 2011). In the Biogeochemistry from the Oligotrophic to the Ultraoligotrophic Mediterranean (BOUM) cruise the ratio of nitrate plus nitrite to phosphate ranged from 24.5 at the surface in the west to 32.4 in the east (Pujo-Pay et al., 2011), far exceeding the canonical Redfield ratio of 16 and distinguishing the Mediterranean Sea as one of the most phosphorus-depleted bodies of water in the world. The major input of water to the Mediterranean is over the shallow sill of the Strait of Gibraltar, bringing in nutrient-depleted surface water from the Atlantic and establishing the oligotrophic nature of the Sea (Krom et al., 1991). The bathymetry and circulation lead to distinctly different water masses in the eastern and western basins with a gradient of nutrients, primary production, and planktonic community structure from west to east (Moutin and Raimbault, 2002; Moutin et al., 2002). During the summer months intense stratification develops in the Mediterranean, leading to a shallow mixed layer that is downwelled in some areas by anticyclonic eddies (Siokou-Fragou et al., 2010; Moutin et al., 2011). Thus the Mediterranean Sea, as

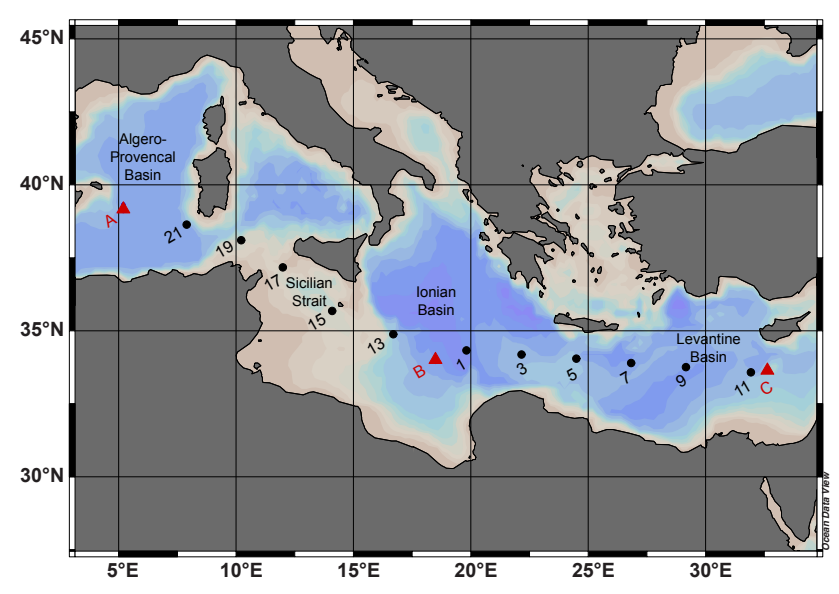

Fig. 1. Map of the Mediterranean Sea, colored to indicate bathymetry, with locations of sampling on the BOUM cruise. Numbered stations (black circles) denote locations where a single depth profile was sampled; lettered stations (red triangles) denote locations where multiple profiles were sampled in near proximity, and where microcosm incubations were conducted.

a contained, highly oligotrophic water mass with a longitudinal gradient of phosphate, provides an excellent study site for the response of IP-DAGs to nutrient limitation.

In this study we set out to see if the phosphorus gradient across the Mediterranean Sea (Krom et al., 1991, Pujo-Pay et al., 2011) leads to a shift in the membrane lipids of marine microbes, where we would expect the oligotrophic conditions in the west to correspond with proportionally more abundant phospholipids than the ultraoligotrophic conditions in the east. In addition, we performed microcosm incubations with nutrient amendments to test whether changes in the available nutrients would elicit a measurable change in IP-DAG composition in a natural, mixed planktonic community on short timescales. These controlled incubations allowed us to assess the relative contribution of physiological response and changes in community composition to the observed changes in IP-DAGs.

\section{Methods}

\subsection{Sampling sites}

This study was conducted as a part of the Biogeochemistry from the Oligotrophic to the Ultraoligotrophic Mediterranean (BOUM) cruise in June-July of 2008 aboard the $\mathrm{R} / \mathrm{V}$ L'Atalante. Samples were collected for IP-DAG quantification along a transect from the Algero-Provencal basin $\left(39.1^{\circ} \mathrm{N}, 5.2^{\circ} \mathrm{E}\right)$ to the eastern Levantine basin near Cyprus $\left(33.7^{\circ} \mathrm{N}, 32.7^{\circ} \mathrm{W}\right.$; Fig. 1$)$. At 11 stations samples for IPDAG depth profiles were collected (numbered stations, 121 ). Each depth profile was composed of nine or ten samples taken between $5 \mathrm{~m}$ and $250 \mathrm{~m}$. At three additional stations 
(lettered stations, station $\mathrm{A}$ in the Algero-Provencal basin, station B in the Ionian basin, and station C in the Levantine basin), located near the center of anticyclonic eddies, multiple depth profiles were collected in close proximity (10 profiles in total). At each of these stations single profiles were taken to greater depths: $2700 \mathrm{~m}, 2500 \mathrm{~m}$, and $900 \mathrm{~m}$ respectively at stations A, B and C. Microcosm incubations with nutrient amendments were also conducted at these stations.

\subsection{Microcosm incubation set up and sampling}

Water for the microcosm incubation was collected with Niskin bottles at $8 \mathrm{~m}$ depth. Each microcosm incubation consisted of triplicate $20 \mathrm{~L}$ carboys for each of four conditions: control $(\mathrm{C})$ no nutrient addition; nitrogen addition (N) with $1600 \mathrm{nM} \mathrm{NH}_{4} \mathrm{Cl}$ at stations $\mathrm{A}$ and $\mathrm{B}, 3200 \mathrm{nM}$ at

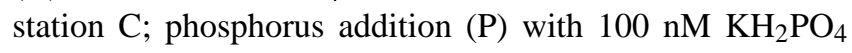
at all stations; nitrogen and phosphorus addition (NP) with $1600 \mathrm{nM} \mathrm{NH} 4 \mathrm{Cl}, 100 \mathrm{nM} \mathrm{KK_{2 }} \mathrm{PO}_{4}$ at stations $\mathrm{A}$ and $\mathrm{B}$, $3200 \mathrm{nM} \mathrm{NH}_{4} \mathrm{Cl}, 100 \mathrm{nM} \mathrm{KH}_{2} \mathrm{PO}_{4}$ at station C. Carboys were incubated in on-deck incubators flushed with surface seawater to maintain ambient temperature, and outfitted with screens to reduce incident light by ca. $50 \%$. Samples were taken daily for a range of biogeochemical parameters (see Tanaka et al., 2011 for full results). Samples were taken for IP-DAGs at the initiation of the experiments and termination, at station $\mathrm{A}$ at the end of three days, at stations $\mathrm{B}$ and $\mathrm{C}$ at the end of four days.

\subsection{IP-DAG sample collection and extraction}

Samples for depth profiles were collected using Niskin bottles mounted on a rosette equipped with sensors for conductivity, temperature, pressure, oxygen, photosynthetically available radiation (PAR), and chlorophyll fluorescence. All samples for IP-DAGs were $1 \mathrm{~L}$, transferred from CTD casts (depth profiles) or incubation carboys (microcosm) to filtration using polycarbonate bottles. Seawater was filtered onto $47 \mathrm{~mm} 0.2 \mu \mathrm{m}$ poresize hydrophilic Durapore filters (Millipore) using gentle vacuum filtration $(<200 \mathrm{~mm} \mathrm{Hg})$. Filters were folded in half, cell side in, wrapped in combusted aluminum foil and stored in liquid nitrogen until extraction. Extraction was conducted using a modified Bligh and Dyer solvent extraction method with phosphatidylethanolamineN-(2,4-dinitrophenyl) (DNP-PE; Avanti Polar Lipids) as an internal recovery standard (Bligh and Dyer, 1959; Popendorf et al., 2011).

\subsection{IP-DAG quantification}

Total lipid extracts were analyzed using high performance liquid chromatography/mass spectrometry (HPLC-MS) with an Agilent 1200 HPLC and Thermo Scientific TSQ Vantage triple quadrupole MS with a heated electrospray ionization (ESI) interface following Popendorf et al. (2011). HPLC methods are given in Sturt et al. (2004). Nine IP-DAGs were quantified: three phospholipids, phosphatidylglycerol (PG), phosphatidylethanolamine (PE), phosphatidylcholine (PC); three glycolipids, sulfoquinovosyldiacylglycerol (SQDG), monoglycosyldiacylglycerol (MGDG), diglycosyldiacylglycerol (DGDG); and three betaine lipids, diacylglyceryl hydroxymethyl-trimethyl- $\beta$-alanine (DGTA), diacylglyceryl trimethylhomoserine (DGTS), and diacylglyceryl carboxyhydroxymethylcholine (DGCC). MS detection and quantification of phospholipids and glycolipids followed the methods given in Popendorf et al. (2011). Additionally, betaine lipids were analyzed. Detection of the betaine lipids was by positive ion mode parent ion scans, for DGTS and DGTA product ion $m / z$ 236; for DGCC product ion $m / z 104$. Quantification of DGCC used an external standard curve prepared with natural DGCC extracted from Thalassiosira pseudonana grown in the Van Mooy lab, purified by preparative HPLC and then quantified by gas chromatography flameionization detector (GC-FID) analysis of transesterified fatty acid methyl esters. The response factor of DGTA on the TSQ MS was established previously using standard curves of DGCC and DGTA prepared in a similar fashion. MS response of DGTS and DGTA were compared on a ThermoFinnigan LCQ Deca XP ion trap MS and the TSQ MS to calculate a response factor for DGTS.

\subsection{Nutrients}

Dissolved nitrate $\left(\mathrm{NO}_{3}^{-}\right)$, nitrite $\left(\mathrm{NO}_{2}^{-}\right)$and phosphate $\left(\mathrm{PO}_{4}^{3-}\right)$ were measured on board using the automated colorimetric technique on a segmented flow Bran Luebbe autoanalyser II; ammonium $\left(\mathrm{NH}_{4}\right)$ determinations were performed on board by fluorometry on a Jasco FP-2020 fluorometer. For full method description see Pujo-Pay et al. (2011). Particulate phosphorus and particulate nitrogen were collected simultaneously on precombusted GF/F filters (Whatman), and were analyzed using the wet-oxidation procedure of PujoPay and Raimbault (1994).

\subsection{Microbial cell abundance}

Abundances of the following microbial populations were assessed using flow cytometry: heterotrophic bacteria, Synechococcus, Prochlorococcus, picoeukaryotic phytoplankton, and nanoeukaryotic phytoplankton. Total cells are presented as a sum of these groups. Full methods for flow cytometry enumeration of both autotrophic and heterotrophic cells are provided in Talarmin et al. (2011) and Tanaka et al. (2011).

\subsection{Chlorophyll}

Depth profiles across the transect were sampled for pigments by filtering $2 \mathrm{~L}$ of seawater onto $25 \mathrm{~mm} \mathrm{GF} / \mathrm{F}$ filters, which were frozen until extraction. HPLC analysis was used to quantify pigments, see Ras et al. (2008) for full analytical methods. Total chlorophyll- $a$ (chl- $a$ ) for the transect depth profiles is reported as a sum of chlorophyll- $a$, divinyl 
chlorophyll- $a$, and chlorophyllide- $a$. For the microcosm incubations, chlorophyll- $a$ was measured fluorometrically, see Tanaka et al. (2011) for complete methods.

\subsection{Statistical treatment of data}

Averages are reported \pm one standard deviation. All reported correlation coefficients are from linear regression analysis. Significant differences in total IP-DAGs and IP-DAG ratios across different nutrient amendments in the microcosm incubations (Fig. 6) were identified by ANOVA and post-hoc Tukey-Kramer HSD tests using MatLab software (version R2009b), at a confidence level of $95 \%$. Principal component analysis (PCA) was conducted using MatLab software (version R2009b) following procedures and code outlined in Glover et al. (2011). The purpose of the PCA was to determine if the variability of individual IP-DAGs was similar to the variability of nutrients $\left(\mathrm{PO}_{4}, \mathrm{NO}_{3}, \mathrm{NH}_{4}\right)$, pigments (chl-a), or microbial groups (Prochlorococcus, Synechococcus, heterotrophic bacteria, picoeukaryotic phytoplankton, nanoeukaryotic phytoplankton). Accordingly a covariance matrix was constructed as the minor product of eighteen standardized parameters; 76 samples were included where each parameter was measured at the same depth from the same CTD cast. Two principal component factors were selected which captured the greatest variability in the data, and the loading of each parameter on the varimax rotation of these two factors is presented. Loadings were considered notable when their absolute values were greater than 0.6.

\section{Results}

\subsection{Environmental conditions across the Mediterranean}

The surface waters of the Mediterranean basins were distinguished by their variation of salinity (Figs. 1 and 2a): relatively low salinity in the Algero-Provencal basin in the west (stations A, 21), and across the Sicilian channel (stations 19 and 15) and the Sicilian strait (station 17), increasing salinity through the Ionian basin (stations 13, B, 1, 3), and highest salinity in the Levantine basin in the east (stations 5, 7, $9,11, C)$. Intense summer stratification was apparent in the potential density ( $\sigma_{\theta}$, Fig. $2 b$ ), which also displayed downwelling at anticyclonic eddies near stations A, B, 9 and C. There was a west-east gradient in phosphate concentration with high phosphate in the west. The phosphocline was shallowest through the Sicilian channel (Fig. 2c) and deepened to the east (Pujo-Pay et al., 2011). Further discussion of the oceanographic conditions during the BOUM campaign are described by Moutin et al. (2011).
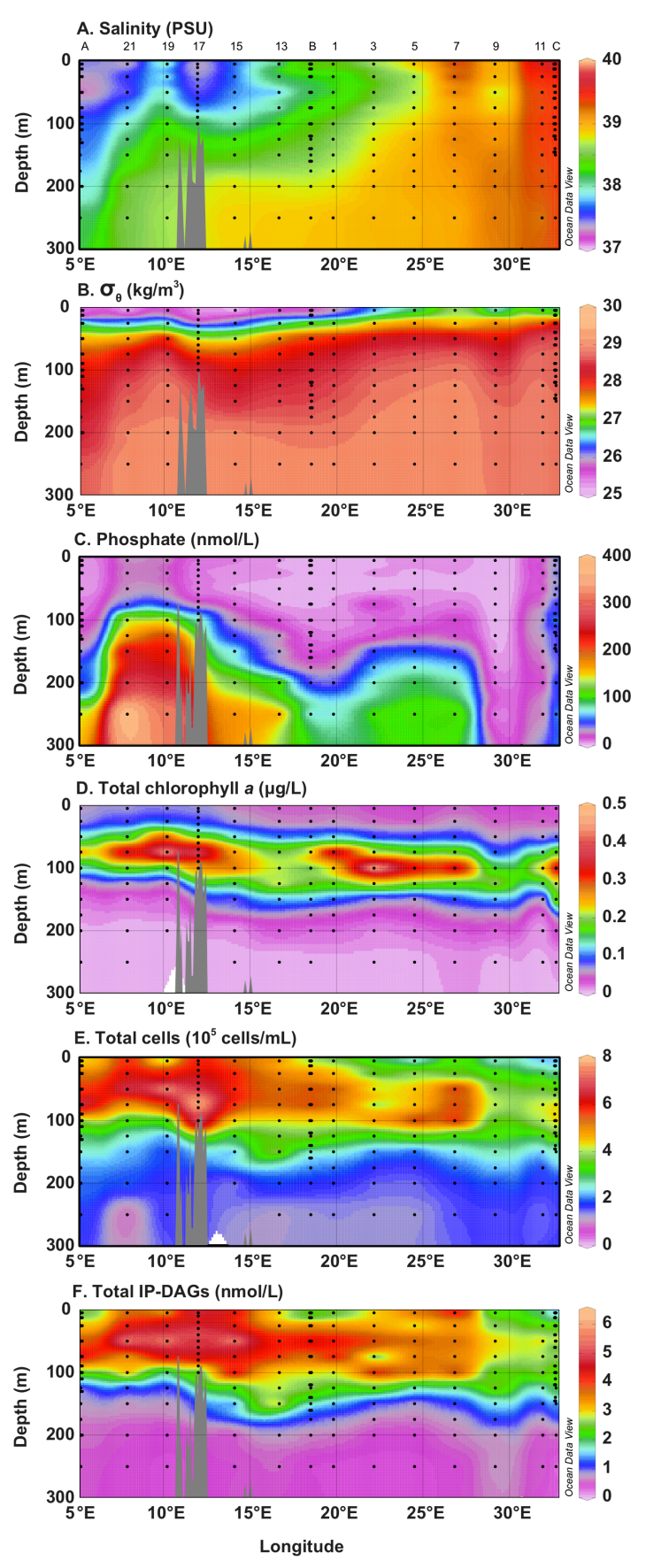

Fig. 2. Distribution of several parameters measured in the upper water column $(300 \mathrm{~m})$ from west to east across the Mediterranean Sea. Salinity (A) and potential density $\left(\sigma_{\theta} ; \mathbf{B}\right)$ were measured with the CTD sensors; phosphate $(\mathbf{C})$ is soluble reactive phosphorus as measured by an autoanalyzer instrument; total chlorophyll- $a(\mathbf{D})$ is the sum of chlorophyll- $a$, divinyl chlorophyll- $a$ and chlorophyllide$a$; total cells (E) is the sum of Prochlorococcus, Synechococcus, heterotrophic bacteria, picoeukaryotic phytoplankton, and nanoeukaryotic phytoplankton; total IP-DAGs $(\mathbf{F})$ is the sum of the nine most abundant classes of IP-DAGs found in the water column. Numbers across the top panel indicate station labels; black dots indicate individual samples, colored contours indicate interpolated gradients. 

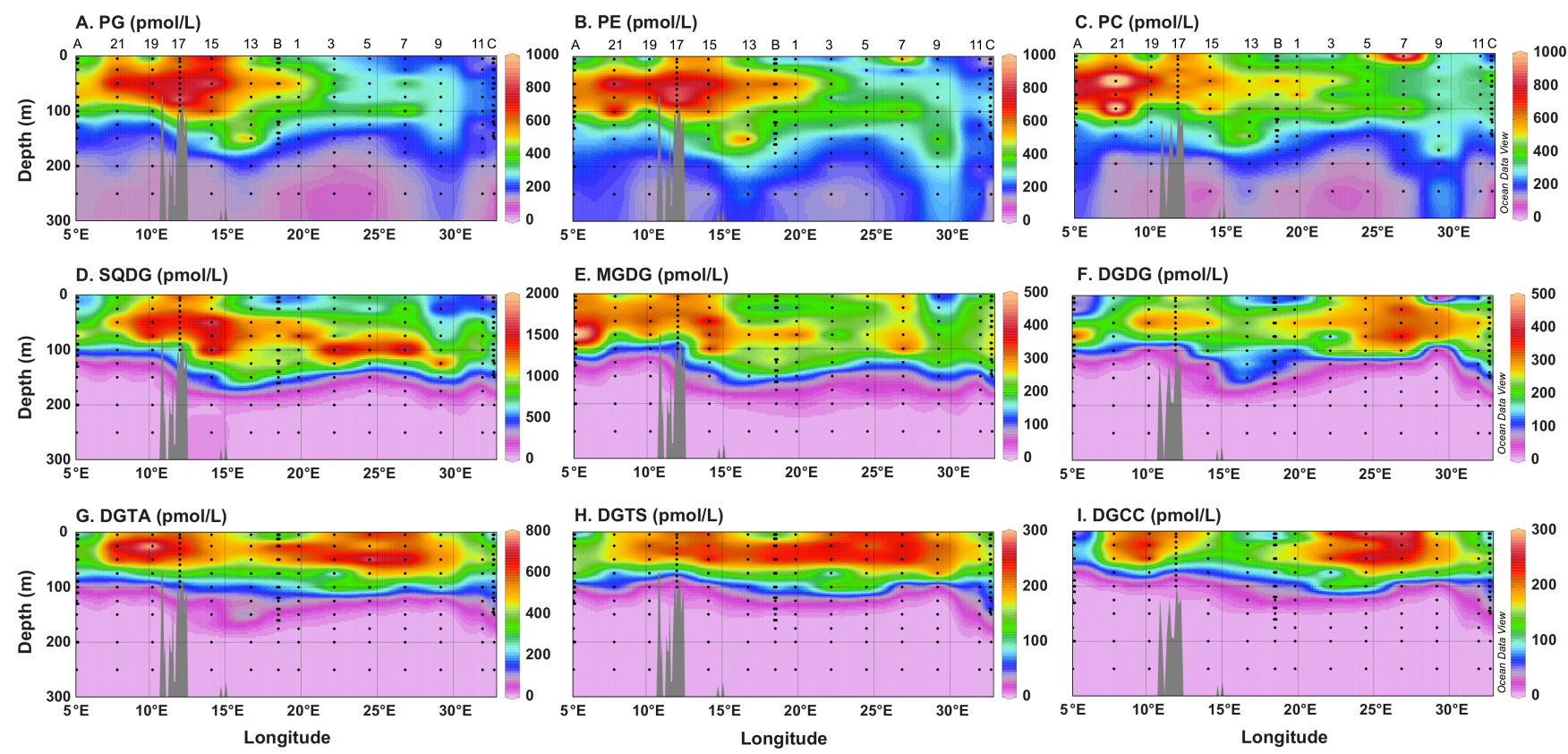

Fig. 3. Distribution of the nine most abundant IP-DAGs in the upper water column $(300 \mathrm{~m})$, each panel showing the concentration of a single class of IP-DAG from west to east across the Mediterranean Sea. The first row (A-C) is phospholipids; the second row (D-F) is glycolipids; the third row (G-I) is betaine lipids. Numbers across the top panels indicate station labels; black dots indicate individual samples, colored contours indicate interpolated gradients.

\subsection{Distribution of IP-DAGs across the Mediterranean}

The IP-DAG membrane lipid composition of particulate material was analyzed at 14 stations across the Mediterranean. In each sample the nine most abundant classes of marine IP-DAGs (Van Mooy and Fredricks, 2010) were quantified: three phospholipids, PG, PE, PC; three glycolipids, SQDG, MGDG, DGDG; and three betaine lipids, DGTA, DGTS, DGCC (Fig. 3). Total IP-DAG concentration, as the sum of these nine classes, averaged $2.4 \pm 1.5 \mathrm{nM}$ in the upper $250 \mathrm{~m}$ of the Mediterranean. The general distribution of total IP-DAGs paralleled that of total cells (Fig. 2), with a significant positive linear correlation $\left(R^{2}=0.64, n=159\right.$, $p<0.01)$. The average IP-DAG content per cell was found to be $6.6 \pm 2.4 \mathrm{amol} / \mathrm{cell}$, or approximately $3.7 \pm 1.3 \mathrm{fg}$ lipid $\mathrm{C} /$ cell (assuming an average IP-DAG molecular weight of $800 \mathrm{~g} \mathrm{~mol}^{-1}$ and $70 \% \mathrm{w} / \mathrm{w} \mathrm{C}$ ). Total lipid concentration was highest in the western Mediterranean with a maximum of $6.3 \mathrm{nM}$ at approximately $50 \mathrm{~m}$ in the Sicilian channel at station 15. The depth of the total IP-DAG maximum deepened from west to east, reaching $100 \mathrm{~m}$ in parts of the Levantine basin and a maximum concentration of only $4.3 \mathrm{nM}$ in the east. The distribution of the total IP-DAGs by depth showed low concentration in the surface $(1.0-5.0 \mathrm{nM})$, a maximum around $50-100 \mathrm{~m}(2.5-6.0 \mathrm{nM})$, and decreasing concentration down to $150 \mathrm{~m}(1.0-3.0 \mathrm{nM})$, then relatively low and constant down to $250 \mathrm{~m}(0.3-0.7 \mathrm{nM}$; Fig. 2). Near the surface, total IP-DAGs were dominated by the glycol- ipids (Fig. 3), closely followed by phospholipids. Averaging across the whole transect, from the surface to $150 \mathrm{~m}$ depth the most abundant IP-DAG was the glycolipid SQDG, roughly $30 \%$ of the total IP-DAGs at many depths, with a maximum of $2.5 \mathrm{nM}$ at $50 \mathrm{~m}$ in the Sicilian strait. Below $150 \mathrm{~m}$ the phospholipid PE was most abundant. The distribution of each lipid class varied both longitudinally and with depth, however the classes within each type of IP-DAG (phospholipids, glycolipids, betaine lipids) tended to have similar characteristics. This was particularly clear in the trends with depth: at depths below approximately $100 \mathrm{~m}$ betaine lipid concentrations decreased sharply; at depths below $150 \mathrm{~m}$ glycolipid concentrations decreased steeply, thus at depths greater than $150 \mathrm{~m}$ phospholipids dominated the reservoir of IP-DAGs (Fig. 3).

\subsection{Variation within types of lipids}

\subsubsection{Phospholipids}

Phospholipids demonstrated a strong longitudinal gradient, with a clear maximum in the west and decreasing concentrations to the east (Fig. 3a, b, c). The phosphate concentration was also higher in the west and decreased to the east (Fig. 2c). As a fraction of total IP-DAGs, total phospholipid concentration (the sum of PG, PE and PC; Fig. 4a) was significantly positively correlated with phosphate concentration $\left(R^{2}=0.30, n=198, p<0.01\right)$. The longitudinal and 


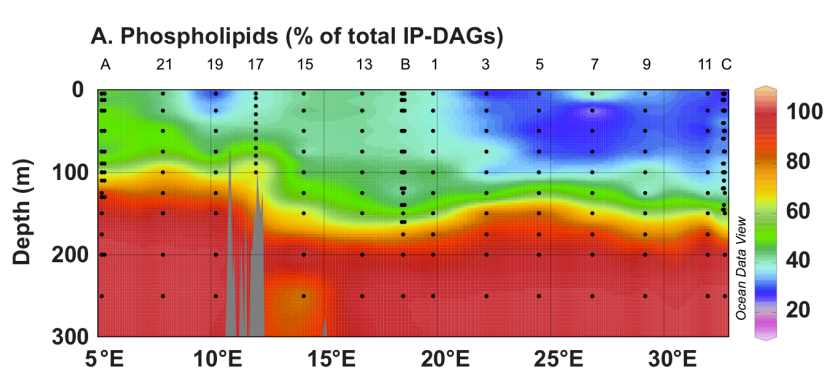

B. Phospholipids (\% of particulate phosphorus)

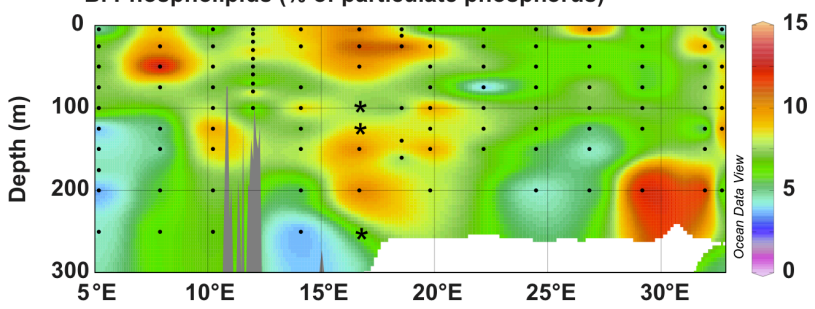
C. SQDG : PG (nM : nM)

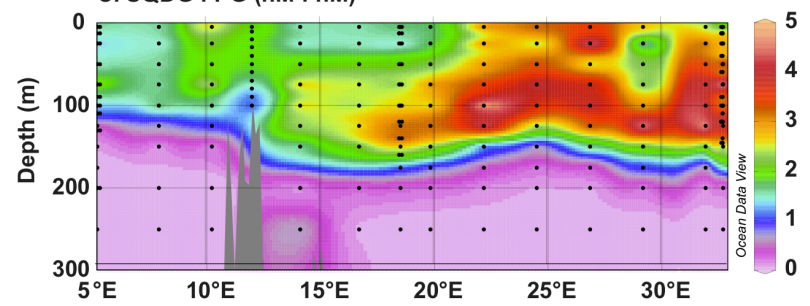

D. Betaine lipids : PC (nM : nM)

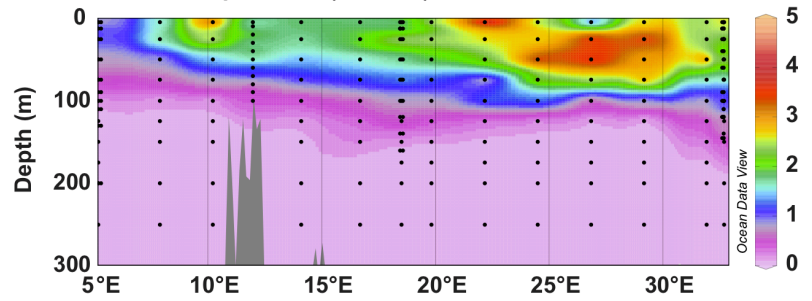

E. SQDG : Total chl a (nM : $\mu \mathrm{g} / \mathrm{L})$

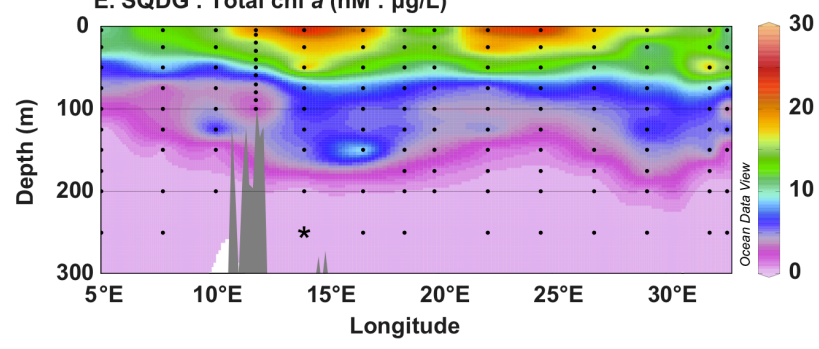

Fig. 4. Distribution of the ratios of lipids each shown in the upper $300 \mathrm{~m}$ from west to east across the Mediterranean Sea. Total phospholipids (the sum of the concentrations of PG, PE and PC) are shown as a percent of total IP-DAGs (A), and as a percent of total particulate phosphorus (B). The ratios of the concentration of nonphosphorus lipids to phospholipids are shown as the ratio of the sulfolipid SQDG to the phospholipid PG (C), and the ratio of the sum of the betaine lipids (DGTA, DGTS and DGCC) to the phospholipid PC (D). Also shown is the ratio of SQDG to total chlorophyll- $a$ (E). Numbers across the top panel indicate station labels; black dots indicate individual samples, colored contours indicate interpolated gradients; * indicates outlier values not plotted. depth distribution of the three phospholipids, $\mathrm{PG}, \mathrm{PE}$, and PC, was quite similar (Fig. 3a, b, c). By depth, each phospholipid class was approximately $200-600 \mathrm{pM}$ in the surface, increasing to $200-800 \mathrm{pM}$ at $50-75 \mathrm{~m}$, then decreasing to $100-200 \mathrm{pM}$ at $250 \mathrm{~m}$. Though the basin-wide distribution of the three phospholipids was similar, their relative abundance varied with depth. From $5 \mathrm{~m}$ to $100 \mathrm{~m}$, PC was the most abundant phospholipid, and in many places the second most abundant IP-DAG after SQDG. At depths below $100 \mathrm{~m}$ PE was the most abundant phospholipid; and below $150 \mathrm{~m} \mathrm{PE}$ was the most abundant IP-DAG. Maxima occurred at station 17 for PG and PE; station 21 for PC; at station 9 high concentrations of all three phospholipids persisted much deeper than the surrounding areas consistent with downwelling seen in isolines (Fig. 2). At several locations samples were taken from $250 \mathrm{~m}$ down to $2500 \mathrm{~m}$ (data not shown); below approximately $175 \mathrm{~m}$ all of the detectable IP-DAGS were phospholipids, which persisted in measurable quantities down to $2700 \mathrm{~m}$ (the deepest depth sampled). At $500 \mathrm{~m}$ and deeper, each phospholipid was roughly $50-100 \mathrm{pM}$, with PE being most abundant (40\% of total IP-DAGs).

\subsubsection{Glycolipids}

In contrast to the phospholipids, the glycolipids did not display a strong longitudinal gradient, nor was their distribution as similar across the three classes of IP-DAGs (Fig. 3d, e, f). By far the most abundant glycolipid was SQDG (Fig. 3d). Its vertical distribution showed a distinct minimum in concentration near the surface, an increase at 50-100 m, and a sharp decrease at $100 \mathrm{~m}$ in the Algero-Provencal basin in the west, a slightly deeper decline at $150 \mathrm{~m}$ to the east. The distributions of MGDG and DGDG were more similar to each other than to SQDG, being less abundant overall $(\sim 200 \mathrm{pM}$ near the surface), and having less pronounced minimums near the surface. DGDG was a little less abundant than MGDG, though MGDG and DGDG both had maxima at $75 \mathrm{~m}$ at station A, roughly 600 and $400 \mathrm{pM}$, respectively.

\subsubsection{Betaine lipids}

The three betaine lipids had similar patterns of distribution (Fig. $3 \mathrm{~g}, \mathrm{~h}, \mathrm{i}$ ), but their absolute concentrations were quite different with DGTA having the highest concentration by a factor of 2 at most locations, a maximum of almost $900 \mathrm{pM}$ compared to roughly $300 \mathrm{pM}$ for DGTS and DGCC. For all three betaine lipids the highest concentration was in the Sicilian channel (stations 19 and 17), with a second maximum in the eastern Mediterranean at the boundary of the Ionian and Levantine basins (stations 3, 5 and 7). Depth profiles of the betaine lipids were different from the phospholipids and glycolipids in several ways: they did not exhibit a pronounced minimum near the surface; the maximum was slightly shallower, $50-75 \mathrm{~m}$ as opposed to $50-100 \mathrm{~m}$; and their concentration decreased more steeply with increasing depth than either 
glycolipids or phospholipids, by $100 \mathrm{~m}$ depth their concentration was near undetectable.

\subsection{Ratio of IP-DAGs}

From west to east across the Mediterranean, the strong gradient of the phospholipids from high to low led to a gradient in the ratio of non-phosphorus lipids to phospholipids (Fig. 4). As a percent of total IP-DAGs, phospholipids averaged $44.3 \%( \pm 10.7 \%$; Fig. $4 \mathrm{a})$ in the upper $100 \mathrm{~m}$ of the Algero-Provencal through the Ionian basins, and 30.0\% $( \pm 7.4 \%)$ in the upper $100 \mathrm{~m}$ of the Levantine basin. Across the Mediterranean, phospholipids were $76.0 \%( \pm 25.7 \%)$ of total IP-DAGs below $100 \mathrm{~m}$ down to $250 \mathrm{~m}$. As a fraction of particulate phosphorus, phospholipids represented $7.1 \%$ $( \pm 2.5 \%)$ of the phosphorus pool (Fig. 4b), with higher values in the west and typically lower values in the surface waters in the east. The fraction of particulate nitrogen represented by N-containing lipids (the sum of PE, PC, DGTA, DGTS and DGCC) was also calculated and found to be $0.4 \%$ ( $\pm 0.2 \%$, data not shown) though there was no notable west to east trend.

The ratio of the sulfolipid SQDG to the phospholipid PG (SQDG:PG; Fig. 4a) was low in the western AlgeroProvencal basin $(1.6 \pm 0.3$ in the upper $100 \mathrm{~m})$, began to increase across the Sicilian channel $(1.9 \pm 0.7$ in the upper $100 \mathrm{~m})$ into the Ionian basin $(2.5 \pm 1.3$ in the upper $150 \mathrm{~m})$, and was highest in the eastern Levantine basin $(3.1 \pm 1.6$ in the upper $150 \mathrm{~m}$ ). The maximum deepened from west to east, from $75 \mathrm{~m}$ in the Algero-Provencal basin to $125 \mathrm{~m}$ in the Levantine basin.

The ratio of the betaine lipids to $\mathrm{PC}$ also exhibited a longitudinal gradient (betaine lipids:PC; Fig. 4b), being lowest in the west $(1.0 \pm 0.5$ in the upper $50 \mathrm{~m}$ in the Algero-Provencal basin) and highest in the east $(2.7 \pm 0.9$ in the upper $75 \mathrm{~m}$ in the Levantine basin). The ratio approached zero at a much shallower depth than SQDG:PG, due to the shallower depths of the betaine lipids relative to SQDG (Fig. 3). The maximum also deepened from west to east, more steeply than SQDG:PG, from near $5 \mathrm{~m}$ in the Sicilian channel to $50 \mathrm{~m}$ in the Levantine basin.

Across the Mediterranean there was a strong positive correlation between SQDG and total chlorophyll- $a\left(R^{2}=0.50\right.$, $n=135, p<0.01)$. The maxima of both SQDG and chl$a$ occurred at depth (Figs. 2 and 3), between 50 and $100 \mathrm{~m}$ (shallower in the western basin, deeper in the eastern basins), however the ratio of SQDG to chl- $a$ was highest near the surface (Fig. 4c). The deep chlorophyll maximum paralleled the abundance of Prochlorococcus (see Mella-Flores et al. (2011) for cyanobacteria abundance), and while the maximum of SQDG also followed the Prochlorococcus abundance, SQDG was also relatively abundant near the surface (Fig. 3d). There was not a longitudinal gradient in SQDG:chl- $a$, with the maxima of the ratio in the Sicilian

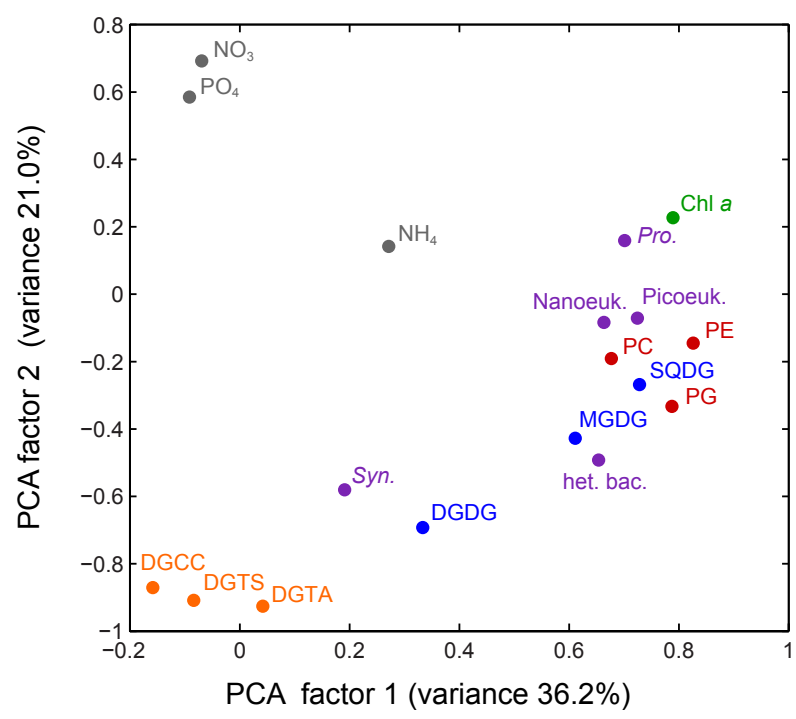

Fig. 5. Principal component analysis was applied to 18 parameters: concentration of three phospholipids (PG, PE, PC; red circles); concentration of three glycolipids (SQDG, MGDG, DGDG; blue circles); concentration of three betaine lipids (DGTA, DGTS, DGCC; orange circles); abundance of five plankton populations (purple circles): Synechococcus (Syn.), Prochlorococcus (Pro.), nanoeukaryotic phytoplankton (nanoeuk.), picoeukaryotic phytoplankton (picoeuk.), heterotrophic bacteria (het. bac.); concentration of three nutrients (grey circles); and concentration of total chlorophyll- $a$ (Chl- $a$; green circle). Each parameter is plotted as its loading on the two principal component factors that captured the greatest amount of variance in the data.

strait (station 15) and across the boundary of the Ionian and Levantine basins (stations 3 and 5).

\subsection{Relationship between IP-DAGs and other biogeochemical parameters}

Principal component analysis (PCA) showed that almost all of the phospholipids and glycolipids had similar loadings on the principal component factor which captured the greatest amount of variance in the data (factor 1, Fig. 5), except for DGDG which loaded heavily on factor 2 . Additionally most of the microbial populations loaded closely to the glycolipids and phospholipids on factor 1, including heterotrophic bacteria, Prochlorococcus, nanoeukaryotic phytoplankton and picoeukaryotic phytoplankton. Synechococcus did not load closely to the other microbial populations on factor 1, though its loadings on both factors 1 and 2 were similar to DGDG. Total chlorophyll- $a$ had similar loading to Prochlorococcus. The nutrients $\mathrm{NH}_{4}, \mathrm{NO}_{3}$, and $\mathrm{PO}_{4}$ did not have loadings similar to any of the cells, chl- $a$, glycolipids or phospholipids in this analysis. However, $\mathrm{NO}_{3}$ and $\mathrm{PO}_{4}$ had heavy positive loadings on factor 2 , while the three betaine lipids had a heavy negative loading on factor 2 , and both nutrients and betaine lipids had similarly little loading on factor 1 . 

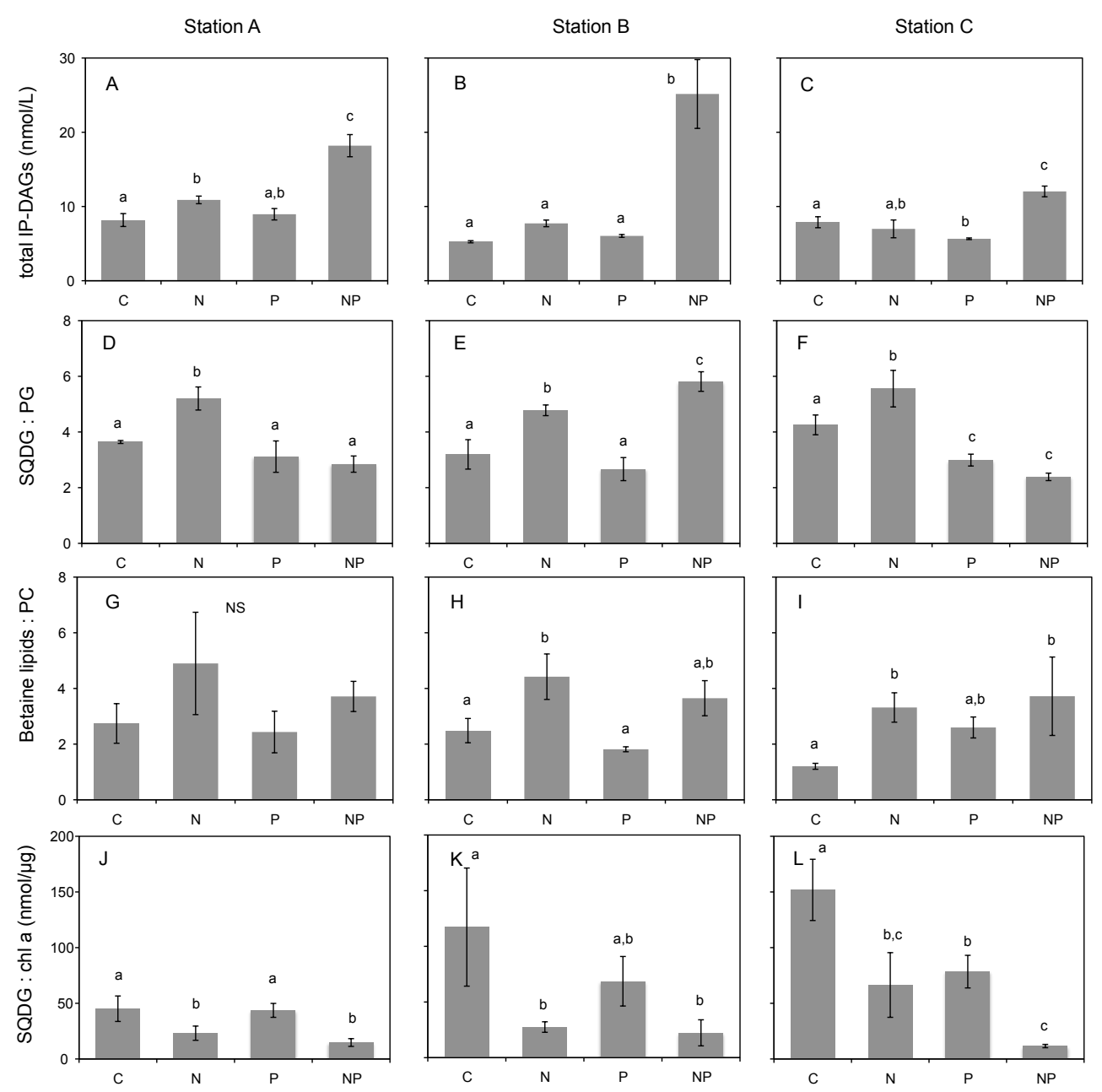

Fig. 6. Total IP-DAG concentration (A-C), SQDG:PG ratio (D-F), betaine lipid:PC ratio (G-I), and SQDG:chlorophyll- $a$ ratio (J-L) on the final day of incubations from three locations, stations $\mathrm{A}, \mathrm{B}$, and $\mathrm{C}$ (organized by column) with nutrient amendments: $\mathrm{C}$ is control (no amendment), $\mathrm{N}$ is addition of ammonium, $\mathrm{P}$ is addition of phosphate, NP is addition of ammonium and phosphate. Error bars are the standard deviation of triplicate carboys. In each plot, lowercase letters $(a, b, c)$ indicate statistical post-hoc comparisons: bars labeled with different letters are significantly different $(p<0.05)$; NS indicates no significant difference.

\subsection{Response of IP-DAGs to nutrient amendments in microcosm incubations}

Microcosm incubations were conducted at three locations (stations $\mathrm{A}, \mathrm{B}$, and $\mathrm{C}$ ) in the Mediterranean to determine the response of the biological community to changes in nutrient availability, specifically an increase in available ammonium ( $\mathrm{N}$ condition), phosphate ( $\mathrm{P}$ condition), or an increase in both ammonium and phosphate (NP condition). Over three or four days an array of biogeochemical parameters were measured to assess community response (see Tanaka 2011 for a full description of results). Comparison of IP-DAGs in the different nutrient amendments on the final day of the incubation showed that within the space of a few days the membrane lipid composition had changed dramatically.
Total IP-DAG concentration increased dramatically in the NP condition in all three experiments (stations A, B and C) relative to the control. With the addition of only ammonium or only phosphate there was a small increase in total IP-DAGs relative to the control at station $\mathrm{A}$ in the $\mathrm{N}$ condition, and a small decrease at station $\mathrm{C}$ in the $\mathrm{P}$ condition (Fig. 6a-c). In contrast to the change in total IP-DAG concentration, the ratio of SQDG to PG increased in the N condition at all three stations. At station $\mathrm{B}$ there was also a large increase in SQDG:PG in the NP condition. At station C there was a small decrease in SQDG:PG in the P condition as well as the NP condition. Shifts in betaine lipid:PC ratio in the $\mathrm{N}$ conditions were similar to those observed in SQDG:PG, with an increase relative to the control at stations B and C (changes were not significant at station A). In contrast to SQDG:PG there also appeared to be an increase in betaine 
lipids:PC in the NP condition at all stations, however the variability across the three triplicates was slightly larger for the betaine:PC ratios than for SQDG:PG and thus the increase in the NP condition was only significant at station C. In the $\mathrm{P}$ condition there were no significant differences in betaine lipids:PC relative to the control.

The ratio of SQDG to chlorophyll- $a$ also changed with nutrient additions, with a decrease in the ratio in both the $\mathrm{N}$ and NP conditions relative to the control at all stations. At station $\mathrm{C}$ there was also a decrease in the $\mathrm{P}$ condition, and no significant change in the $\mathrm{P}$ condition at the other two stations.

\section{Discussion}

Membrane lipids have a rich history of being applied as a proxy for microbial biomass in the environment (Balkwill et al., 1988, White et al., 1979), and recent work has shown that they may also be applied as indicators of community structure and physiology (Popendorf et al., 2011; Van Mooy et al., 2006, 2009). In this study, across the Mediterranean total cell abundance was highest in the west (Fig. 2) as expected from previous studies (Siokou-Frangou et al., 2010 and references therein), and total IP-DAG concentration was significantly positively correlated with total cell abundance. Though the distribution of cell size has also been observed to vary across the Mediterranean (Christaki et al., 2011; Siokou-Frangou et al., 2010), and could contribute to the variation in IP-DAG content per cell, apparently the variation in cell size has a smaller influence on IP-DAG concentration than cell abundance. Among the different IP-DAGs the strongest west to east gradient was seen in the phospholipids. When normalized to total IP-DAGs, the gradient of phospholipids was positively correlated with phosphate concentration, with phospholipids making up less of the membrane lipids in the surface waters of the ultraoligotrophic east. This aligns with the hypothesis that microbes will direct less of their cellular phosphate towards phospholipid production when the nutrient is increasingly scarce (Van Mooy et al., 2006, 2009). Indeed, phospholipids were generally a higher percent of particulate phosphorus in the west and lower in the east. With less phospholipids in the membrane, the balance of IP-DAGs is expected to come from glycolipids and betaine lipids. The particular substitutions that have been observed in cultures are SQDG substituting for PG, and betaine lipids substituting for PC (Benning et al., 1993, 1995; Martin et al., 2011; Van Mooy et al., 2006, 2009). Across the Mediterranean, the ratios of SQDG:PG and betaine lipids:PC were both highest in the east. This gradient in membrane composition corresponded with the change in nutrients across the Mediterranean (Pujo-Pay et al., 2011), however there are two potential mechanisms that could contribute to this variation in IP-DAGs: (1) physiological shifts within organisms, leading to increased non-phosphorus lipids per cell, or (2) changes in the composition of the microbial community leading to more abundant low-phospholipid containing organisms (for example Synechococcus; Popendorf et al., 2011; Van Mooy et al., 2006) when phosphorus is scarce. By combining measurements of IP-DAGs across the Mediterranean with measurements in microcosm incubations we were able to deconvolve the relative contribution of these two mechanisms.

\subsection{Factors influencing IP-DAG ratios}

The relative influence of community composition and physiological response to nutrients was assessed by principal component analysis (Fig. 5), comparing the variability in IP-DAG concentrations to the variability in nutrients and variability in the abundances of different planktonic groups. All of the microbial groups, except for Synechococcus, loaded heavily on factor 1 and only minimally on factor 2 , thus factor 1 loads heavily on parameters representing community structure. Additionally, all of the phospholipids and glycolipids, except DGDG, load heavily on factor 1 and not heavily on factor 2, indicating that much of the variability in phospholipids and glycolipids across the transect might be associated with the variability in the planktonic community. Synechococcus and DGDG did not load heavily on factor 1 , but they loaded closely to each other on factor 2 . Previous studies have shown that DGDG is a significant component of Synechococcus membranes and is not as abundant in other cyanobacterial or heterotrophic bacterial membranes (Popendorf et al., 2011). Furthermore, the distribution across the transect showed that maxima of both DGDG and MGDG corresponded with high abundances of Synechococcus and Prochlorococcus respectively (see Mella-Flores et al. (2011) for the distribution of cyanobacteria). The similar loading of Prochlorococcus and chl- $a$ in the PCA also corresponded with the observed co-occurrence of the deep chlorophyll maximum and Prochlorococcus maximum across the Mediterranean, further affirming the utility of the PCA. Similar associations between Prochlorococcus and chlorophyll$a$ were previously observed in the South Pacific (Van Mooy and Fredricks, 2010).

The other parameters that did not load heavily on factor 1 were nutrient concentrations and betaine lipid concentrations, which instead loaded heavily on factor 2 . This may indicate that across the Mediterranean the concentration of betaine lipids was heavily influenced by the concentration of nutrients, implying a stronger signal of physiological response as opposed to variation in community structure. Though principal component analysis is a useful tool for indicating potential connections it cannot determine if community or physiology are causal in the variability of IP-DAGs. The variation of IP-DAGs with different microbial groups has been well studied in cultures (Oliver and Colwell, 1973; Guschina and Harwood, 2006; Kato et al., 1996; Van Mooy et al., 2006), and some work has also been done measuring the diversity of IP-DAGs in microbial groups from environmental samples (Popendorf et al., 2011). The physiological 
response has also been well studied in monocultures (Benning et al., 1993, 1995; Martin et al., 2011; Van Mooy et al., 2009), however it remains to be shown whether the influence of changes in physiology can be detected in changes in IP-DAGs in a natural, mixed planktonic community.

\subsection{Influence of physiology vs. community on IP-DAGs assessed in microcosm incubations}

The microcosm incubations with nutrient amendments conducted on the BOUM cruise provided a unique opportunity for assessing the relative contributions of community composition and physiological response to the changes in IP-DAGs. Within the microcosms, we could account for changes in the community composition, enabling an examination of the changes in IP-DAGs that resulted from solely physiological adaptation. The addition of nitrogen and phosphorus to the oligotrophic, phosphate-depleted waters of the Mediterranean elicited a diverse array of both community and physiologic shifts in the microbial community.

With the addition of phosphate ( $\mathrm{P}$ condition) in the microcosms no significant changes were observed in the abundance of various microbial groups (Tanaka et al., 2011). With the lack of change in community composition, the observed change of IP-DAGs in this condition would be expected to be primarily due to physiological response. However, primary production, bacterial production, and alkaline phosphatase activity did not change in response to the $\mathrm{P}$ amendment (Tanaka et al., 2011; Lagaria et al., 2011), which indicates that this system was not phosphate limited despite the low ambient phosphate concentration and high $\mathrm{N}: \mathrm{P}$ at all three stations (Pujo-Pay et al., 2011). Relative to the control, phosphate addition elicited a change in the ratio of IP-DAGs at only one station: a small decrease in SQDG:PG at station $\mathrm{C}$, as would be expected of a physiological response to increased phosphate. At all other stations there were no significant changes in the ratio of SQDG:PG or betaine lipids:PC. This lack of strong response to phosphorus addition is consistent with the observations of a previous phosphate addition experiment in the Mediterranean (Thingstad et al., 2005), which found that increased phosphate did not elicit a change in the phytoplankton community despite the expectation of phosphate limitation. The lack of observed shifts in IP-DAG ratios simply reflects a community that was not P-limited.

The addition of ammonium ( $\mathrm{N}$ condition), on the other hand, elicited a strong physiological response. In the $\mathrm{N}$ condition alone there was a significant increase in alkaline phosphatase activity at all three stations (Tanaka et al., 2011), demonstrating clear enhancement of phosphorus stress (Lomas et al., 2010). The changes in IP-DAG ratios that were observed are what would be expected from a physiologic response to increased phosphorus stress: at all three stations the ratio of SQDG:PG increased, and at two stations the ratio of betaine lipids:PC increased relative to the control (changes were not significant at station A, although the mean was higher). These changes were consistent across the stations, despite inconsistent changes in the community structure which were generally small relative to changes observed in the NP condition (Tanaka et al., 2011). Thus these changes in IP-DAG ratios indicate that the increase in phosphorus stress led to a dynamic, physiologic cellular response resulting in IP-DAG substitution in a natural, mixed planktonic community. This is the first observation of a change in membrane composition as a physiological response in the environment, and it indicates that elevated ratios of these IPDAGs observed in other phosphate depleted environments could be an indicator of phosphorus stress.

The increase of the betaine lipid: $\mathrm{PC}$ ratio in the $\mathrm{N}$ condition provided validation of the lipid substitution expected from observations in culture (Benning et al., 1995; Martin et al., 2011). This was particularly notable since betaine lipids in marine environments are not well understood (Van Mooy and Fredricks, 2010; Popendorf et al., 2011) and therefore mechanistic explanations for the observed trends are more limited. In all of the amendment conditions the change in betaine lipids:PC was more variable within the triplicate measurements than the change in SQDG:PG. The PCA indicated that betaine lipids might be more strongly influenced by physiological response than the glycolipids or phospholipids (Fig. 5), and the longitudinal trend in the betaine:PC ratio showed an increase in the ultraoligotrophic eastern Mediterranean Sea (Fig. 4), indicating an increase in response to low phosphate conditions as expected. However the sharp decrease in betaine lipid abundance with depth, relative to glycolipids and phospholipids, indicates that the abundance of these IP-DAGs may be controlled by unique factors, related either to physiology or community, which are thus far unidentified. The microcosm incubations support the conclusion that physiological response contributes to the observed trends in betaine lipid concentration, but future studies could further refine our understanding of betaine lipid sources and the factors that influence them.

In the NP condition there was a significant change in both the community composition and metabolic activity at all three stations. These changes included an increase in primary production at all three stations, an increase in bacterial production at stations $\mathrm{B}$ and $\mathrm{C}$, and an increase in the abundance of many microbial groups including Synechococcus (all stations), autotrophic nanoplankton (stations B and C), and ciliates (stations A and C; Tanaka et al., 2011; Lagaria et al., 2011). The total IP-DAG concentration increased significantly at all three stations, as would be expected from the large increase in microbial abundance. The significant shifts in community structure, however, meant that little insight on physiology could be drawn from the observed changes in IPDAG ratios. 


\subsection{Relationship between SQDG and chlorophyll-a}

Previous studies have suggested that SQDG originates solely in photoautotrophic organisms (Popendorf et al., 2011; Van Mooy et al., 2006, 2009) and is associated with the organelles of photosynthesis (Sakurai et al., 2006; Sato, 2004; Wada and Murata 1998). Thus we would predict that across the Mediterranean there would be a strong correlation between SQDG and chlorophyll- $a$, and indeed this was observed. The maxima of both SQDG and chlorophyll- $a$ occurred at depth, however the ratio of SQDG to chlorophyll- $a$ was highest near the surface. While the maximum of SQDG paralleled the maximum in Prochlorococcus abundance (MellaFlores et al., 2011), SQDG is known to also occur in other phytoplankton including Synechococcus and pico- and nanoeukaryotic phytoplankton (Popendorf et al., 2011; Sato, 2004; Van Mooy et al., 2006, 2009), which were more abundant near the surface than at the deep chlorophyll maximum (Mella-Flores et al., 2011). The increase in the ratio of SQDG to chlorophyll- $a$ near the surface therefore indicates that though both molecules correlate with phytoplankton abundance, their ratio varies with depth. This may be due to a combination of both photoacclimation, decreasing cellular chlorophyll content with high surface irradiance (MacIntyre et al., 2002), or higher cellular SQDG content in the phytoplankton species that are more abundant near the surface.

Though no longitudinal gradient was observed in SQDG:chl- $a$, the change in the ratio in the microcosm incubations demonstrated a response to changes in nutrients. In the N and NP conditions at all stations the ratio of SQDG to chlorophyll- $a$ decreased significantly relative to the control (at station $\mathrm{C}$ the ratio decreased relative to the control in all amendment conditions). This change in the $\mathrm{N}$ condition is likely representative of a physiological response (as previously discussed the changes in the NP condition are likely due to a combination of community changes and physiological response). Chlorophyll has a high nitrogen content, and is known to increase proportionally more than phytoplankton abundance when nitrogen is added to an $\mathrm{N}$-starved system (Zohary et al., 2005). The addition of ammonium in these incubations led to an increase in chlorophyll- $a$ in the $\mathrm{N}$ condition relative to the control at stations $\mathrm{A}$ and $\mathrm{B}$ (Tanaka et al., 2011), and, though the ratio of SQDG:PG was seen to increase in these conditions, the ratio of SQDG:chl$a$ decreased, indicating that this ratio is sensitive to nitrogen abundance. Thus the ratios of SQDG:chl- $a$, as an indicator of nitrogen availability, and SQDG:PG, as an indicator of phosphorus stress, may be complementary indicators of planktonic nutrient stress in oligotrophic marine environments.

\section{Conclusions}

We observed gradients in IP-DAGs that correlated with the phosphate gradient across the Mediterranean, which is consistent with the hypothesis that nutrient availability controls the relative abundance of IP-DAGs. Gradients in community structure undoubtedly contributed to this gradient, but our microcosm incubations showed that physiological shifts likely also contribute to the observed changes. The phospholipid concentration as a percent of total lipids was positively correlated with phosphate concentration across the Mediterranean, both phospholipids and phosphate concentration being higher in the west and lower in the east. Glycolipids and betaine lipids did not show a strong west to east gradient, however the ratio of non-phosphorus lipids to phospholipids varied across the Mediterranean, with SQDG:PG and betaine lipids:PC being higher in the ultraoligotrophic eastern Mediterranean. Throughout the Mediterranean, total IP-DAGs in the upper $250 \mathrm{~m}$ were correlated with cell abundance, reaffirming their direct representation of microbial biomass in the ocean. Comparison of the variation in IPDAGs to variations in microbial groups and nutrients across the Mediterranean was used to examine the relative influence of microbial community composition changes and cellular physiology changes on the observed IP-DAG changes. Microcosm incubations of whole seawater with nutrient amendments provided further insight on these two mechanisms, and provided direct evidence from a mixed community under in situ conditions that shifts in IP-DAG ratios are part of a physiologic response to changes in nutrients. Additionally, the microcosm incubations demonstrated that an increase in ammonium led to a decrease in the ratio of SQDG to chl- $a$, indicating that this ratio may be an indicator of nitrogen availability. With knowledge of the factors influencing the variation of IP-DAGs in the environment, IP-DAGs can be molecular tools for the study of the microbes in the ocean and their role in biogeochemical cycles.

Acknowledgements. The authors would like to thank the captain and crew of the R/V L'Atalante, Josephine Ras and Hervé Claustre for the chlorophyll data (HPLC method), Stella Psarra for contributions to chlorophyll data (fluorometry method) and helpful comments on the manuscript, Helen Fredricks for HPLC-MS guidance, Krista Longnecker for assistance culturing T. pseudonana for the DGCC standard, Catherine Carmichael for her aid in quantifying the DGCC standard, Patrick Martin for his work with MS betaine comparisons, James Fulton for helpful discussions, and all of the scientists who participated in and contributed to the BOUM cruise. Additional thanks to two anonymous reviewers for helpful suggestions during the open review process. Funding for this work was provided by a grant from the National Science Foundation (OCE-0646944 and OCE-1031143).

Edited by: C. Jeanthon 


\section{References}

Balkwill, D. L., Leach, F. R., Wilson, J. T., McNabb, J. F., and White, D. C.: Equivalence of microbial biomass measures based on membrane lipid and cell wall components, adenosine triphosphate, and direct counts in subsurface aquifer sediments, Microbial Ecol., 16, 73-84, 1988.

Benning, C., Beatty, J. T., Prince, R. C., and Somerville, C. R.: The sulfolipid sulfoquinovosyldiacylglycerol is not required for photosynthetic electron transport in Rhodobacter sphaeroides but enhances growth under phosphate limitation, Proc. Natl. Acad. Sci., 90, 1561-1565, 1993.

Benning, C., Huang, Z.-H., and Gage, D. A.: Accumulation of a Novel Glycolipid and a Betaine Lipid in Cells of Rhodobacter sphaeroides Grown under Phosphate Limitation, Arch. Biochem. Biophys., 317, 103-111, 1995.

Bligh, E. G. and Dyer, W. J.: A Rapid Method of Total Lipid Extraction and Purification, Canad. J. Physiol. Pharmacol., 37, 911917, 1959.

Christaki, U., Van Wambeke, F., Lefèvre, D., Lagaria, A., Prieur, L., Pujo-Pay, M., Grattepanche, J.-D., Colombet, J., Psarra, S., Dolan, J. R., Sime-Ngando, T., Conan, P., Weinbauer, M. G., Moutin, T.: Microbial food webs and metabolic state across oligotrophic waters of the Mediterranean Sea during summer, Biogeosciences, 8, 1839-1852, doi:10.5194/bg-8-1839-2011, 2011.

Glover, D. M., Jenkins, W. J., and Doney, S. C.: Principal Component and Factor Analysis, in: Modeling Methods for Marine Science, Cambridge University Press, London, UK, 571, 2011.

Guschina, I. A. and Harwood, J. L.: Lipids and lipid metabolism in eukaryotic algae, Progress in Lipid Research, 45, 160-186, 2006.

Kato, M., Sakai, M., Adachi, K., Ikemoto, H., and Sano, H.: Distribution of Betaine Lipids in Marine Algae, Phytochemistry, 42, 1341-1345, 1996.

Krom, M. D., Kress, N., Brenner, S., and Gordon, L. I.: Phosphorus limitation of primary production in the eastern Mediterranean Sea, Limnol. Oceanogr., 36, 424-432, 1991.

Lagaria, A., Psarra, S., Lefèvre, D., Van Wambeke, F., Courties, C., Pujo-Pay, M., Oriol, L., Tanaka, T., and Christaki, U.: The effects of nutrient additions on particulate and dissolved primary production and metabolic state in surface waters of three Mediterranean eddies, Biogeosciences, 8, 2595-2607, doi:10.5194/bg8-2595-2011, 2011.

Lomas, M. W., Burke, A. L., Lomas, D. A., Bell, D. W., Shen, C., Dyhrman, S. T., and Ammerman, J. W.: Sargasso Sea phosphorus biogeochemistry: an important role for dissolved organic phosphorus (DOP), Biogeosciences, 7, 695-710, doi:10.5194/bg-7-695-2010, 2010.

MacIntyre, H. L., Kana, T. M., Anning, T., and Geider, R. J.: Photoacclimation of photosynthesis irradiance response curves and photosynthetic pigments in microalgae and cyanobacteria, J. Phycol., 38, 17-38, 2002.

Martin, P., Van Mooy, B. A. S., Heithoff, A., and Dyhrman, S. T.: Phosphorus supply drives rapid turnover of membrane phospholipids in the diatom Thalassiosira pseudonana, The ISME Journal, 5, 1057-1060, 2011.

Mella-Flores, D., Mazard, S., Humily, F., Partensky, 5 F., Mahé, F., Bariat, L., Courties, C., Marie, D., Ras, J., Mauriac, R., Jeanthon, C., Bendif, E. M., Ostrowski, M., Scanlan, D. J., and Garczarek, L.: Is the distribution of Prochlorococcus and Synechococcus ecotypes in the Mediterranean Sea affected by global warm- ing?, Biogeosciences Discuss., 8, 4281-4330, doi:10.5194/bgd8-4281-2011, 2011.

Minnikin, D. E., Abdolrahimzadeh, H., and Baddiley, J.: Replacement of acidic phospholipids by acidic glycolipids in Pseudomonas diminuta, Nature, 249, 268, 1974.

Moutin, T. and Raimbault, P.: Primary production, carbon export and nutrients availability in western and eastern Mediterranean Sea in early summer 1996 (MINOS cruise), J. Mar. Syst., 33-34, 273-288, 2002.

Moutin, T., Thingstad, T. F., Van Wambeke, F., Marie, D., Raimbault, P., Slawyk, G., and Claustre, H.: Does competition for nanomolar phosphate supply explain the predominance of the cyanobacterium Synechococcus?, Limnol. Oceanogr., 47, 15621567, 2002.

Moutin, T., Van Wambeke, F., and Prieur, L.: The Biogeochemistry from the Oligotrophic to the Ultraoligotrophic Mediterranean (BOUM) experiment, Biogeosciences Discuss. 8, 80918160, doi:10.5194/bgd-8-8091-2011, 2011.

Oliver, J. D. and Colwell, R. R.: Extractable Lipids of GramNegative Marine Bacteria: Phospholipid Composition, J. Bacteriol., 114, 897-908, 1973.

Popendorf, K. J., Lomas, M. W., and Van Mooy, B. A. S.: Microbial sources of intact polar diacylglycerolipids in the Western North Atlantic Ocean, Org. Geochem., 42, 803-811, 2011.

Pujo-Pay, M., Raimbault, P.: Improvement of the wet-oxidation procedure for simultaneous determination of particulate organic nitrogen and phosphorus collected on filters, Mar. Ecol. Press Ser., 105, 203-207, 1994.

Pujo-Pay, M., Conan, P., Oriol, L., Cornet-Barthaux, V., Falco, C., Ghiglione, J.-F., Goyet, C., Moutin, T., and Prieur, L.: Integrated survey of elemental stoichiometry $(\mathrm{C}, \mathrm{N}, \mathrm{P})$ from the western to eastern Mediterranean Sea, Biogeosciences, 8, 883899, doi:10.5194/bg-8-883-2011, 2011.

Ras, J., Claustre, H., and Uitz, J.: Spatial variability of phytoplankton pigment distributions in the Subtropical South Pacific Ocean: comparison between in situ and predicted data, Biogeosciences, 5, 353-369, doi:10.5194/bg-5-353-2008, 2008.

Rütters, H., Sass, H., Cypionka, H., and Rullkötter, J.: Phospholipid analysis as a tool to study complex microbial communities in marine sediments, J. Microbiol. Meth., 48, 149-160, 2002.

Sakurai, I., Shen, J.-R., Leng, J., Ohashi, S., Kobayashi, M., and Wada, H.: Lipids in Oxygen-Evolving Photosystem II Complexes of Cyanobacteria and Higher Plants, J. Biochem., 140, 201-209, 2006.

Sato, N.: Betaine Lipids, The Botanical Magazine, Tokyo, 105, 185-197, 1992.

Sato, N.: Roles of the acidic lipids sulfoquinovosyl diacylglycerol and phosphatidylglycerol in photosynthesis: their specificity and evolution, J. Plant Res., 117, 495-505, 2004.

Siokou-Frangou, I., Christaki, U., Mazzocchi, M. G., Montresor, M., d'Alcalá, M. R., Vaqué, D., and Zingone, A.: Plankton in the open Mediterranean Sea: a review, Biogeosciences, 7, 15431586, doi:10.5194/bg-7-1543-2010, 2010.

Sturt, H. F., Summons, R. E., Smith, K., Elvert, M., and Hinrichs, K.-U.: Intact polar membrane lipids in prokaryotes and sediments deciphered by high-performance liquid chromatography/electrospray ionization multistage mass spectrometry-new biomarkers for biogeochemistry and microbial ecology, Rapid Comm. Mass Spectrom., 18, 617-628, 2004. 
Suzumura, M. and Ingall, E. D.: Concentrations of lipid phosphorus and its abundance in dissolved and particulate organic phosphorus in coastal seawater, Mar. Chem., 75, 141-149, 2001.

Talarmin, A., Van Wambeke, F., Catala, P., Courties, C., and Lebaron, P.: Flow cytometric assessment of specific leucine incorporation in the open Mediterranean, Biogeosciences, 8, 253265, doi:10.5194/bg-8-253-2011, 2011.

Tanaka, T., Thingstad, T. F., Christaki, U., Colombet, J., CornetBarthaux, V., Courties, C., Grattenpache, J.-D., Lagaria, A., Nedoma, J., Oriol, L., Psarra, S., Pujo-Pay, M., and Van Wambeke, F.: Lack of P-limitation of phytoplankton and heterotrophic prokaryotes in surface waters of three anticyclonic eddies in the stratified Mediterranean Sea, Biogeosciences, 8, 525-538, doi:10.5194/bg-8-525-2011, 2011.

Thingstad, T. F., Krom, M. D., Mantoura, R. F. C., Flaten, G. A. F., Groom, S., Herut, B., Kress, N., Law, C. S., Pasternak, A., Pitta, P., Psarra, S., Rassoulzadegan, F., Tanaka, T., Tselepides, A., Wassmann, P., Woodward, E. M. S., Riser, C. W., Zodiatis, G., and Zohary, T.: Nature of phosphorus limitation in the ultraoligotrophic eastern Mediterranean, Science, 309, 1068-1071, 2005.

Van Mooy, B. A. S., Rocap, G., Fredricks, H. F., Evans, C. T., and Devol, A. H.: Sulfolipids dramatically decrease phosphorus demand by picocyanobacteria in oligotrophic environments, P. Natl. A. Sci., 103, 8607-8612, 2006.

Van Mooy, B. A. S., Moutin, T., Duhamel, S., Rimmelin, P., and Wambeke, F. V.: Phospholipid synthesis rates in the eastern tropical South Pacific Ocean, Biogeosciences, 5, 133-139, http://www.biogeosciences.net/5/133/2008/, 2008.
Van Mooy, B. A. S., Fredricks, H. F., Pedler, B. E., Dyhrman, S. T., Karl, D. M., Koblížek, M., Lomas, M. W., Mincer, T. J., Moore, L. R., Moutin, T., Rappé, M. S., and Webb, E. A.: Phytoplankton in the ocean substitute phospholipids in response to phosphorus scarcity, Nature, 458, 69-72, 2009.

Van Mooy, B. A. S. and Fredricks, H. F.: Bacterial and eukaryotic intact polar lipids in the eastern subtropical South Pacific: Watercolumn distribution, planktonic sources, and fatty acid composition, Geochim. Cosmochim. Ac., 74, 6499-6516, 2010.

Wada, H. and Murata, N.: Membrane Lipids in Cyanobacteria, in: Lipids in Photosynthesis: Structure, Function and Genetics, edited by: Siegenthaler, P.-A. and Murata, N., Kluwer Academic Publishers, The Netherlands, 65-81, 1998.

Wakeham, S. G., Hedges, J. I., Lee, C., Peterson, M. L., and Hernes, P. J.: Compositions and transport of lipid biomarkers through the water column surficial sediments of the equatorial Pacific Ocean, Deep-Sea Res. Pt. II, 44, 2131-2162, 1997.

White, D. C., Davis, W. M., Nickels, J. S., King, J. D., and Bobbie, R. J.: Determination of the Sedimentary Microbial Biomass by Extractible Lipid Phosphate, Oecologia, 40, 51-62, 1979.

Zohary, T., Herut, B., Krom, M. D., Mantoura, R. F. C., Pitta, P., Psarra, S., Rassoulzadegan, F., Stambler, N., Tanaka, T., Thingstad, T. F., and Woodward, E. M. S.: P-limited bacteria but $\mathrm{N}$ and $\mathrm{P}$ co-limited phytoplankton in the Eastern Mediterranean - a microcosm experiment, Deep-Sea Res. Pt. II, 52, 3011-3023, 2005. 